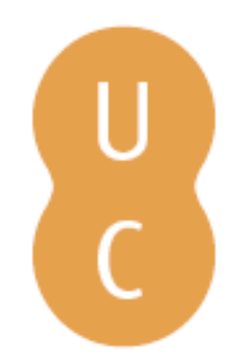

\title{
pompalina
}

\section{O canto do martírio: espírito agónico no humanismo}
Autor(es):
Urbano, Carlota Miranda
Publicado por: Imprensa da Universidade de Coimbra
URL persistente:
URI:http://hdl.handle.net/10316.2/38375
DOI:
DOI:http://dx.doi.org/10.14195/978-989-26-0371-1_13

Accessed : $\quad$ 26-Apr-2023 10:51:01

A navegação consulta e descarregamento dos títulos inseridos nas Bibliotecas Digitais UC Digitalis, UC Pombalina e UC Impactum, pressupõem a aceitação plena e sem reservas dos Termos e Condições de Uso destas Bibliotecas Digitais, disponíveis em https://digitalis.uc.pt/pt-pt/termos.

Conforme exposto nos referidos Termos e Condições de Uso, o descarregamento de títulos de acesso restrito requer uma licença válida de autorização devendo o utilizador aceder ao(s) documento(s) a partir de um endereço de IP da instituição detentora da supramencionada licença.

Ao utilizador é apenas permitido o descarregamento para uso pessoal, pelo que o emprego do(s) título(s) descarregado(s) para outro fim, designadamente comercial, carece de autorização do respetivo autor ou editor da obra.

Na medida em que todas as obras da UC Digitalis se encontram protegidas pelo Código do Direito de Autor e Direitos Conexos e demais legislação aplicável, toda a cópia, parcial ou total, deste documento, nos casos em que é legalmente admitida, deverá conter ou fazer-se acompanhar por este aviso.

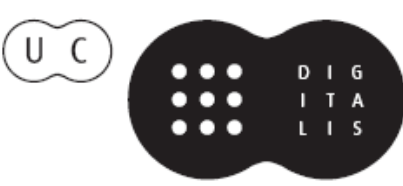


FRANCISCO DE OLIVEIRA

Coordenação

Ospírito Olímpico

no

novo milénio 
O CANTO DO MARTÍRIO: ESPÍRITO AGÓNICO NO HUMANISMO

Carlota Miranda Urbano Universidade de Coimbra

No âmago do "espírito olímpico" que dá o tema a este congresso, reside a corrida para a meta da glória. A corrida, o combate, a prova que coloca o homem contra o outro homem, a competir pela vitória, aquilo a que chamamos espírito agónico e que o mundo grego admiravelmente encarnou em tantas dimensões da sua vida, é decerto mais do que a competição. É uma luta do homem para se superar a si mesmo, para superar os seus limites e a sua caducidade. Por isso, nós encontramos ao longo da história e das realizações humanas a força deste espírito. Testemunham- no, por vezes, belos passos da literatura.

Esta comunicação pretende ocupar-se de um poema do séc. XVII que exalta um herói da ascese e do martírio. Francisco Pacheco, um jesuíta, que nos anos da perseguição do cristianismo entre os nipónicos, prossegue os seus trabalhos de evangelização, acaba por ser preso e juntamente com os companheiros é queimado vivo. Aqui temos o mártir, mais tarde beatificado por Pio IX, apresentado como herói de uma notável epopeia de doze cantos, o Padecidos libri duodecim( ( editado pela primeira vez em Coimbra no ano de 1640, da autoria de

(') Sobre este poema veja-se TORRES, Amadeu, "A Arquidiocese de Braga e a Expansão da Fé: Nos 350 anos da "Padecidos Libri XIГ, sep. de Homenagem à Arquidiocese Primaz nos 900 anos da Dedicação da Catedral, Lisboa, Academia Portuguesa da História, 1993, p.XLVII (1995) 861-870. O poema conheceu para além da edição de 1640, uma segunda edição em Génova no ano de 1750 e uma terceira do século XIX: Grandpont, Guichont. La Paciecide Épopée en douze livres en I'honneur du très illustre Père François Pacheco, portugais de Ponte de Lima (...) par Barthélemy Pereira, S.J. (...) Paris, 1887. 
Bartolomeu Pereira( $\left.{ }^{2}\right)$, um poeta também jesuíta mestre de Artes em Coimbra.

1 Não podemos deixar de visitar Pindaro, o eterno cantor dos heróis olímpicos, para brevemente lançarmos um olhar sobre os caminhos percorridos pelo espírito agónico e pelos sentidos da ascese, que em primeiro lugar é o exercício do atleta que o leva à perfeição e à vitória. Pindaro assume a missão sagrada de exaltar o herói vencedor, mas também a cidade da sua origem, e o herói do mito que escolheu para ilustrar e significar na sua composição. O amor da glória, a base da educação homérica, é o nobre ideal do herói, e este passa a constituir exemplum, a fornecer modelos que despertarão no ouvinte espírito agónico. Não podemos demorar-nos com Pindaro, mas fixemos a perspectiva de Jacqueline Ducheminí3) sobre a sua obra que nos ajudará a reconhecer no séc. XVII este espírito olímpico.

No entender da autora, no centro das preocupações de Pindaro está o problema escatológico, mas não vamos tão longe. Atentemos apenas no seguinte: Duchemin, baseando-se na leitura dos mitos narrados nas odes, afirma que em Pindaro, se por um lado o nascimento do herói ocorre de algum modo prodigiosamente, e se alguns heróis são favorecidos pelos deuses desde o nascimento, o que lhes confere uma natureza divina, por outro, esses favores são merecidos, e o homem deve encontrar pelo seu próprio esforço os valores da civilização e da humanidade, que só pode alcançar à custa da ascese. Aqueles que neste combate conseguem superar a condição humana, alcançam a glória, a sua parte na herança sobrenatural, que lhes merece um hino divino e lhes garante partilhar a imortalidade dos deuses. $\left({ }^{4}\right)$

2 Mas vejamos de que valor a designação do exercício e do treino

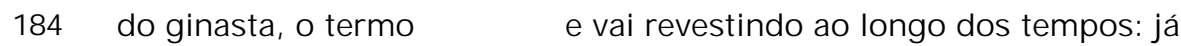

(2) Para alguns dados biográficos sobre este autor veja-se Miranda URBANO, Carlota, "Cantus Conuiualis no canto I do Padecidos libri duodecim de Bartolomeu Pereira SJ" Humanitas LI (1999) 285- 299.

(3) DUCHEMIN, Jacqueline, Pindare poète et prophète, Paris, 1955.

(4) Veja-se a obra acima citada, especialmente a segunda parte, "Le message Pindarique et la tradition" 97- 190. 
em Pindaro e em Herodoto o termo adquirira o sentido espiritual do exercício da virtude, e também em Xenofonte e em Platão.

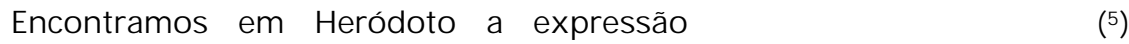

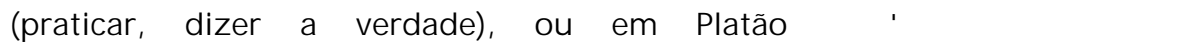
$\left.\alpha \sigma \kappa \varepsilon \nu^{6}{ }^{6}\right)$ (praticar a sabedoria e a virtude), isto para dar apenas

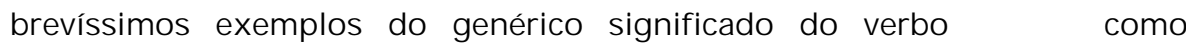
prática ou exercício de uma virtude.( $\left.{ }^{7}\right)$

Em Xenofonte há uma ocorrência a registar, pois relaciona as duas vertentes do sentido da ascese: nos Memoráveis, este autor diz-nos que, do mesmo modo que aquele que não exercita o corpo não consegue realizar as proezas do corpo, também aquele que não exercita o espírito não consegue realizar as proezas do espírito.(8)

Conceito importante nos filósofos estoicos, a ascese tem já em Epicteto, o filósofo do período imperial romano, a raiz da posterior ascese entendida como a adopção voluntária de privações e renúncias. No Encheiridion aconselha, por exemplo, o seguinte: "se queres treinar a resistência física, fá-lo para ti mesmo e não para os outros; quando tiveres muita sede, põe água fresca na boca e cospe-a, e não digas a ninguém. .."(9)

Mas é em Filon de Alexandria, o filósofo do judaísmo helenístico, que encontramos mais desenvolvido o conceito de ascese, tal como Posteriormente o vão divulgar os primeiros séculos do cristianismo. A sua obra resulta de influências da doutrina judaica, mas também da obra de Platão que conheceu em profundidade, e também, concerteza das influências do estoicismo tão divulgado na sua época. Em Filon, a ascese entra no âmbito de uma ética teológica, ganha o sentido de luta e treino, físico e espiritual, com ênfase no domínio dos desejos e na abstenção do prazer. Os que praticam a moderação e a frugalidade,

(5) Herodotus, VII, 209, p 524, Loeb Classical Library.

(6) Platão, Euthydemus 283a.

(7) Veja-se, no entanto uma ocorrência do verbo com o sentido diverso de 'praticar o

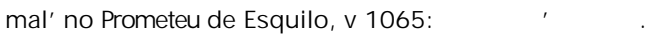

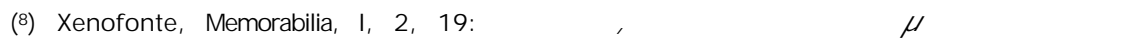

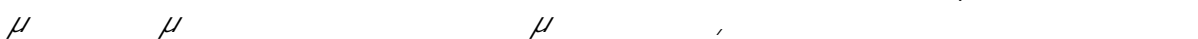

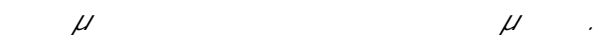

(9) Epicteto, Encheiridion 47. 
segundo Filon, possuirão a abundância, é o que nos diz na sua obra Acerca dos prémios e dos castigos.(10)

A ascese que os primeiros padres da Igreja divulgam, embora entronque no Novo Testamento, na metáfora atlética de S. Paulo que foi objecto de trabalho da minha colega, a Dr. Paula Barata Dias, essa ascese, dizia, tem uma das suas raízes em Filon, sobretudo no sentido da renúncia e nos estoicos, especialmente no conceito de purificação da alma das suas paixões.

Se nos primeiros séculos do cristianismo a ascese encontrou expressão sobretudo na preparação para o martírioO · ), com o fim das perseguições, o 'negar-se a si mesmo' das mais variadas formas, por exemplo pela vida monacal, é o modo de praticar o glorioso feito dos mártires.

A crescente devoção da Idade Média pela humanidade de Cristo e pela sua Paixão e morte aumenta nos fiéis o desejo de conformação com os sofrimentos do Redentor, surgem as ordens mendicantes, que assumem a pobreza voluntária e das quais nascem numerosos tratados sobre a ascese. No séc. XV, a famosa Imitação de Cristo, de Thomas Van Kempen, contribui para o desenvolvimento de uma nova doutrina de vida interior baseada numa ascese exigente, a devotio moderna.

Porém, algum humanismo do Renascimento, por um lado, e a Reforma protestante, por outro, reagem contra o ideal ascético. Sobretudo a Reforma Protestante, com a doutrina luterana da justificação apenas pela fé, abala os fundamentos teológicos da ascese medieval. Só a fé e a Graça salvam o homem que nada pode. Contra esta aniquilação das possibilidades humanas, o sentido antiluterano da contrarreforma

(10) Filon, De praemiis et poenis 100.

(>') Nos primeiros séculos do cristianismo, o conflito ético-religioso entre o império romano e as comunidades cristãs gera inúmeros mártires. Pressionados pelos seus súbditos inconformados com a fuga dos cristãos à tradição, os imperadores perseguem e condenam o cristianismo. O martírio exerceu então uma forte atracção para muitos cristãos, o que testemunha, por exemplo, Tertuliano em obras como Ad martyras. Neste texto, nas suas exortações, Tertuliano recorre à comparação com os atletas, com os gladiadores, com o mundo militar, o que sublinha a concepção heroica que este autor tem da fé cristã. Veja-se p. ex.: "Proinde uos, benedicti, quodcumque hoc durum est, ad exercitationem uirtutum animi et corporis deputate. Bonum agonem subituri estis in quo agnothetes Deus uiuus est, xystarches Spiritus Sanctus, corona aeternitatis, brabium angelicae substantiae, politia in caelis, gloria in saecula saeculorum" Cf. Ad martyra, III, 3. 
investe com o conceito de virtude heroica que os santos encarnam, conceito que sem dúvida deriva do humanismo e de uma radical confiança no homem(12). A Reforma Católica continua a fazer a apologia e a gerar "campeões" da ascese, e surgem novas ordens religiosas que dão expressão a uma ascese mais exclusivamente interior, a completa renúncia da vontade, é o caso da Companhia de Jesus.

3 Esta ordem missionária cuja notável empresa educativa é sobejamente conhecida, foi também extremamente actuante nos domínios espiritual e teológico. Neste último, destacamos o aspecto mais relevante para este trabalho, o seu contributo na controversa polémica da cooperação da Graça Divina com o livre arbítrio do homem, que não moveu apenas, como vemos, o mundo protestante, mas que opôs dominicanos e jesuítas(13). Valerá ao homem o seu esforço para se salvar? Basta-lhe a fé? questões cujas respostas darão ou não sentido ao ideal ascético.

No domínio espiritual o pequeno livro de St. Inácio de Loiola, recheado de imagens medievais e de espiritualidade tradicional nos seus pontos particulares, foi sem dúvida extremamente inovador se entendermos o seu todo significativo, a sua proposta de ascese, o seu método e a sua perspectiva humanista.

Também neste ponto deveríamos deter-nos sobre a ascese inaciana que influenciou largamente não só os religiosos da Companhia que regularmente faziam os Exercícios Espirituais, mas numerosos leigos que orientados por jesuítas os faziam, no contexto desta Devotio Moderna alargada a todos os fiéis.

(12) Veja-se a propósito do conceito de virtude heroica na Contra- Reforma MAIO, Romeo de, Riforme e miti del'500, Guida Editori Napoli, 197, p.257-278. Fazendo um estudo dos processos de canonização na Conta-Reforma, o autor propõe uma leitura da evolução da concepação de virtude heroica.

(13) Controversa acesa com a publicação de uma obra do jesuíta Luis de Molina, que saiu em Lisboa no ano de 1588 e que se propunha conciliar a eficácia universal da Graça com o livre arbítrio do homem à luz da presença de Deus e atacava expressamente a doutrina tomista do dominicano Bafiez exposta no seu Comentário a S. Tomás, publicado em 1584. Veja-se a este propósito ISERLOH, Glazik ejedin Storia de la Chiesa - Riforma e Controriforma, vol. VI, ed. Jaca Book, 1975, p.656- 659. 
Antes de mais, importa notar que o livro do fundador da Companhia não é nem pretende ser um tratado sobre a ascese, nem se dirige sequer ao que faz os Exercícios, ele é sim um manual de instruções, dirigido ao professor de ginástica (deixai passar a metáfora), ou se quisermos, ao guia espiritual que orienta os Exercícios. Só este facto já nos permite suspeitar da presença influente de um espírito agónico (de luta), de uma constante disciplina e exercício na concepção inaciana da vida espiritual do fiel cristão.

Se o tempo permitisse uma visita pormenorizada aos pontos dos exercícios, às suas regras e anotações, veríamos aquela suspeita confirmada, mas vejamos apenas um tema dominante. Para além das imagens fortemente inspiradas pelo clima militar e cavaleiresco medieval e os valores dele herdados, da devoção, da obediência, do serviço a um Senhor, domina os Exercícios, como meio para atingir o supremo fim de dar maior Glória a Deus, o "Vencer-se a si mesmo". A todo o momento o homem trava este Agón, este combate que opõe as duas bandeiras, o estandarte de Cristo e o de Lúcifer, ou se quisermos as duas cidades, Jerusalém e a Babilónia, numa evocação da imagem desenvolvida por St. Agostinho no De Ciuitate Dei.

Nas adições da primeira Semana, St. Inácio aponta como segundo fim da penitência: "Vencer-se a si mesmo, a saber, para que a sensualidade obedeça à razão e todas as partes inferiores estejam mais sujeitas às superiores"(14). Isto implica, pois, o domínio do corpo, que no decurso dos Exercícios se traduz em gestos de disciplina que ajudarão a alcançar esta virtude. Por ex. a penitência corporal, o refrear dos sentidos, o guardar silêncio, a pontualidade a levantar-se, etc...

Os frutos de um vencer-se a si mesmo contínuo, e não apenas no decurso dos Exercícios, são o "ordenar-se", a libertação das paixões, a paz, acompanhada das três virtudes da humildade, da paciência e da 188 fortaleza.

Notemos então que na ascese inaciana a penitência não é um fim, mas um exercício que serve para o aperfeiçoamento constante das virtudes interiores. A suma perfeição destes "atletas" deve ser

(14) Inácio DE Loiola, Exercícios Espirituais, trad. de Vital Dias Pereira S J, Porto, 1983. Cf. 887 . 
procurada, seja qual for o seu estado de vida(15), e implica "sair do seu próprio amor, querer e interesse^16), de modo a que não se queira nem deseje mais do que Deus quer, ou pelas palavras de St. Inácio: “de tal maneira que da nossa parte, não queiramos mais saúde que doença, riqueza que pobreza, honra que desonra, vida longa que breve, e, assim, por diante em tudo o mais, somente desejando e escolhendo o que mais nos conduz para o fim que somos criados/W)

A ascese inaciana é sem dúvida um dos traços mais vigorosos e peculiares do espírito da Reforma Católica, e é também à luz das propostas deste movimento que devemos entender o Poema de Bartolomeu Pereira em louvor do martírio de Francisco Pacheco.

4 A recusa da Reforma protestante ao culto dos santos e das relíquias dos mártires teve como contrapartida na Reforma Católica, um ressurgimento da hagiografia em que a tendência apologética recua para dar lugar ao método crítico. No entanto, continuamos a encontrar numerosos poemas em tom épico que fazem a apologia de santos e mártires e a par dessa tendência, assistimos à intensificação do culto das relíquiasO ${ }^{8}$ ).

A semelhança de Roma, igreja fundada sobre a fé dos apóstolos e sobre as relíquias de $\mathrm{S}$. Pedro e S. Paulo, todas as outras igrejas procuram ter relíquias de santos e mártires ligados às suas origens, e no

(15) Ibidem $\$ 135$ "como nos devemos dispor para chegar à perfeição em qualquer estado de vida que Deus, Nosso Senhor, nos conceder escolher"; §173 "Se alguém fez eleição devida e ordenadamente (...) não tem motivo para de novo fazer eleição, mas aperfeiçoe- se naquela que fez, quanto puder"; §185 "Supor a um homem que nunca vi nem conheci. $\mathrm{E}$, desejando- Ihe eu toda a sua perfeição, considerar o que eu the diria que ele fizesse e elegesse para maior glória de Deus, nosso Senhor e maior perfeição de sua alma (...)". A glória de Deus acompanha sempre a perfeição da alma.

(16) Ibidem $\$ 189$ "porque pense cada um que tanto aproveitará em todas as coisas espirituais quanto sair do seu próprio amor, querer e interesse."

(17) Ibidem §23, o chamado Princípio e Fundamento. Espécie de texto programático que abre a Primeira Semana e tem como objectivo predispor o exercitante para o percurso espiritual que se segue.

(18) O Agiologio Lusitano de George Cardoso, que começou a ser editado em I 652, atesta bem o especial valor que esta época atribui à veneração das relíquias dos santos e mártires. CARDOSO, Jorge, Agiologio Lusitano dos sanctos e varoens illustres em virtude do reino de Portugal e suas conquistas, Lisboa, 1652- 1774. 
Jubileu do ano 1600, afluem a S. Pedro um milhão e duzentos mil peregrinos para venerar as sagradas relíquiasí19). A Igreja pós-tridentina, reafirma o culto dos santos também prescrevendo para uso litúrgico em 1584 o Martyrologium Romanum compilado pelo Cardeal Sirleto a encargo de Gregório XIII.

A Sé Nova de Coimbra, antiga igreja do Colégio de Jesus da Companhia deste nome, cuja construção terminou já no séc. XVII, é um claro exemplo da valorização das relíquias, a julgar pelas enormes paredes que encerram os extremos do seu transepto, revestidas de numerosos relicários ricamente ornados. Como sugere o Prof. Doutor Américo da Costa Ramalho, é muito provável que algumas destas relíquias provenham da Igreja de S. Roque, também da Companhia de Jesus, que em 1588 recebeu numerosas relíquias que o embaixador joão de Borja trouxe da Alemanha e de outros locais onde corriam risco de profanação graças os cisma protestante. A importância das relíquias neste tempo é testemunhada pela própria celebração deste acontecimento que deu lugar à publicação de um livro de poesias de vários humanistas celebrando o acontecimento.ín)

Nesta atmosfera, então, podemos entender melhor a epopeia de doze cantos, cerca de seis mil versos, cujo propósito é cantar o martírio do Beato Francisco Pacheco.

5 E sobretudo no Canto $V$, a narrativa da prisão do herói-mártir, mas também no Canto XII, a narrativa da morte e glorificação, que se torna mais expressivo o espírito olímpico de um Agón que é travado nos planos divino e humano. Palco de uma luta entre dois mundos e suas

(19) Este ano assiste ao triunfo de um papado renovado, nos países católicos, favorecido pelo Concílio de Trento que lentamente via as suas reformas postas em prática. Quando Clemente VIII abriu a Porta Santa em 31 de Dezembro de 1599, estavam presentes 80.000 pessoas.

(20) Entre os quais se encontra p. ex. André Falcão de Resende, como informa RAMALHO, Américo da Costa, in O essencial sobre André Falcão de Resende. Cf. p 19-20: "Com efeito, vemo-lo colaborar com oitavas e sonetos, na Companhia de Pero de Andrade Caminha, Diogo Bernardes, Luis Franco, do licenciado Fernão Rodrigues Lobo e outros, entre os quais o licenciado Manuel Campos que foi o editor, na Relaçaam do solenne recebimento que se fez em Lisboa às santas relíquias que se levaram à Igreja de S. Roque da Companhia de Jesus." 
forças contrárias, Francisco Pacheco, como qualquer herói, caracteriza- se por uma natureza agónica.(21)

Podemos ver em quase todo o poema um claro paralelismo entre este mártir-herói e o herói olímpico, entre a poesia que louva e imortaliza os heróis dos jogos helénicos e esta epopeia que louva os heróis da Evangelização. O atleta corre para a sua glória, que será a vitória sobre a sua caducidade, a sua imortalização na memória através da poesia que o cantará. O mártir corre ad Maiorem Dei Gloriam. Saindo derrotado pelas forças do mal aos olhos do mundo, vencido sai vitorioso, porque glorificado, também ele eternizado na Glória de Deus e na memória dos fiéis. Também ele luta contra a sua caducidade, contra os seus limites, exercitando-se nas virtudes, vencendo-se a si mesmo para que nele triunfe a sua centelha divina.

O constante sofrimento que a prisão impõe a Pacheco e aos seus companheiros é a sua melhor arma para se fortalecerem e prepararem para o martírio. A ausência de conforto e de repouso, bem como as mais diversas torturas contribuem para a ascese que os purifica, no dizer do poeta: "em tais sofrimentos, porém, a mais bela virtude alimenta as forças e uma valentia secreta"(22). Por isso, quando abranda a tortura, "logo cada um flagela o seu corpo com o chicote, como se travasse combate com impudente inimigo e não cessam os golpes de suas próprias mãos, até que o último suspiro lhes foge da boca, as correias caiem das mãos e o chão fica rubro de sangue"."'(23)

Assim fortalecidos pela penitência exterior, estes heróis não têm qualquer cuidado pelas coisas mundanas e pensam apenas em "crucificar o seu corpof,(24). Francisco Pacheco, o herói protagonista anseia e suspira por mais sofrimentos, por que venha finalmente o martírio, e cito - "nas lágrimas recrudesce o seu amor e recobra as forças adormecidas"(25)

(21) BAUZÁ, Hugo, na sua obra $\boxminus$ mito del héroe, morfologia e semântica de la figura heroica, El Salvador, 1998, caracteriza o herói como alguém que está em permanente conflito entre dois mundos. Cf. p.8.

(22)Traduzido nas citações. Padecidos... V, v. 107- 108.

(23) Ibidem V, v. 126- 130.

(24) Ibidem V, v. I 33.

(25) Ibidem V, v. 154. 
Vencedores neste combate humano entre a esperança e a tortura, o "rei do funesto Averno"(26), no dizer do poeta, prepara nova ofensiva a estes heróis. Pede a Vénus que envie o seu filho Amor com suas flechas e com elas vença Pacheco e os seus companheiros, já que as torturas nada conseguiram. Trava-se então um combate divino entre o Cego Amor, como Ihe chama o poeta, e a Pureza. Falando a Pacheco durante o sono, o Amor propõe-lhe, em troca da apostasia, o casamento com a bela filha de Mondo, e recorda- Ihe célebres e míticos vencidos das suas setas, para que não pense resistir-lhe. A Pureza acode a Pacheco, insulta o Amor Cego, expulsa-o e desmascara o seu engano, porque, cito - "até quando dorme, Pacheco vigia, triunfa durante o sono"(27). O Amor tenta ainda vencer os companheiros do herói, mas também eles levam a palma da vitória neste combate, então, desistindo corre a chorar, humilhado, para o regaço consolador da sua mãe que promete vingança a Pacheco. O resultado desta vitória é a glorificação da virtude dos heróis, numa antevisão da sua glorificação pelo martírio. Cito: "irefulgiu a honra da virtude...todo o rigor, todas as ameaças começaram a ceder"(28). Os guardas não só refreiam as suas torturas, mas fazem tudo para aliviar os sofrimentos dos prisioneiros. O poeta manda calar Orfeu, pois, mais do que o seu canto que domou as feras, as obras(29) destes prisioneiros abrandaram os corações de pedra dos seus carrascos.

Ao ver surgir esta oportunidade, Francisco Pacheco propõe à contemplação destes homens uma série de exempla, homens e mulheres, naturais do Japão, que sofreram o martírio, modelos em que venceu a virtude, e deste modo se converte um jovem guarda.

6 A morte e a apoteose de Francisco Pacheco, encerram o último canto da epopeia, e estes momentos são também eles representativos 192 do ideal do mártir-herói.

(26) Ibidem, V, v. 165.

(27) Ibidem V, v.236- 238.

(28) Ibidem V, v.276- 278.

$\left(2^{9}\right)$ Valorize-se aqui o carácter eficaz das obras no contexto da polémica questão da justificação das almas entre a doutrina luterana e a católica. 
Francisco Pacheco, que o poeta compara ao cisne, canta o momento da morte, exulta neste trespasse que é o triunfo, a meta tão desejada da sua corrida para a glória. Cito as suas palavras:

0 fogueira!, ó meta tão desejada das minhas preces, como a vossa demora afligia o meu peito, afligia a minha alma, mas chegastes, enfim; em boa-hora vinde, para que pelo fogo me purifique (...) Recebei nas vossas cinzas este corpo envelhecido, ó chamas, que o nosso zelo e as nossas lágrimas mereceram, e o mar tantas vezes percorrido, e os mil perigos enfrentados nas ondas. Feliz aquele a quem foi dado passar pelo fogo e pelas águas! De um lado e do outro conspiram água e fogo, ambos elevam aos céus a minha glória.(30)

O perfil heroico de Pacheco surge, assim, valorizado na dolorosa e trágica morte pelo fogo. Além disso, esta morte significa simbolicamente a purificação do herói, a redução de tudo o que nele é humano e imediata libertação da sua centelha divina que se reunirá ao seio divino de Deus Pai. (31)

Aquelas palavras do herói exprimem o desejo de martírio, a máxima conquista a que aspiravam os santos, a sua forte consciência de heroísmo, de honra e de glória tão gratas ao seu tempo.

O grande movimento missionário desencadeado pelas descobertas de novos mundos traz consigo novas oportunidades de manifestação daquele desejo, e se o martírio não se trava contra as autoridades ou religiões locais, como neste caso, há outras formas de o travar, pelo 'serviço heroico', como o exprimem sobretudo as ordens hospitaleiras de S. João de Deus e de S. Camilo de Lellis. A morte por contágio com a peste, fruto do serviço aos doentes, é considerada um forma de martírio, também ela resulta de uma escolha voluntária de Cristo nos pobres e doentes(32). Este é sem dúvida um ideal heroico valorizado na

(39) Padecidos ... op.cit, XII, v. I 17- 126.

(3) BAUZÁ, op. cit., no estudo do mito do herói na Antiguidade Clássica, percorre os caminhos de Hércules, como arquétipo do herói, observando o carácter paradigmático da sua apoteose pelo fogo. Cf. p.80-82. A obra dedica àquele herói todo o capítulo III "Heracles y el arquétipo heroico" p.39- 106.

(32) O Agiologio Lusitano, no seu prefácio, justifica a inclusão de "alguns religiosos, que movidos de caridade ministrando os sacramentos aos feridos da peste ou curandoos, morreram nesta sã empresa, a cujos semelhantes a Igreja Católica em lata significação dá título de mártires." E justifica-a evocando um antigo exemplo "Assi o faz o martyrologio romano a 28 de Fevereiro a certos presbyteros, diaconos e seculares de Alexandria, os 
sociedade da Reforma Católica que mais uma vez se afirma na polémica com as doutrinas protestantes que desvalorizam a acção humana e fazem depender apenas da Graça de Deus a Salvação do homem. Ao mesmo tempo, este ideal mostra na sua época o elevado valor do martírio cantado nesta epopeia.

Mas o triunfo do mártir, aos olhos do mundo, é uma derrota, por isso Francisco Pacheco apela à cristandade do Japão que não o lamente, mas que antes contribua para a sua glorificação, exultando também de alegria com a vitória do seu 'atleta':

E vós, meu rebanho, celebrai comigo este dia, todos vós, cingidos de coroas festivas, e erguei nas mãos as palmas. (...) uma só coisa vos peço, vos suplico nesta hora extrema: que nenhum de vós, ó Japão, me desonre com suas lágrimas, ao verme arder entre as chamas e as duras cadeias. Ao triunfo não ficam bem os tristes lamentos $>$ \33)

Não podemos deixar de notar a coroa festiva e a palma, prémio das vitórias nas competições da Antiguidade, que para sempre ficaram na simbologia da iconografia cristã como identificação da vitória do martírio.

Enquanto arde o fogo que consome estes mártires, Francisco Pacheco, a Fénix( $\left.{ }^{(34}\right)$, como Ihe chama o poeta, parte para os céus, juntamente com os companheiros, guiados pelo anjo Japoniel, o anjo do Japão. Os mártires chegam à mansão celestial, brilham as nove palmas e as nove coroas destinadas a cada um. Acolhem-nos à chegada, St. Inácio

quaes numa cruel peste q naquella cidade ouue an. 255 mouidos de Caridade acudirão com grande cuidado (como quem sacrificava a vida por Cristo) os sacerdotes, \& diaconos a Sacramentar os enfermos \& consolalos, \& os seculares com outros de Menores Ordens, a curalos, a servilos e enterralos, offerecendose huns e outros voluntariamente á morte". Cf. p.50. Esta 'categoria' de santos merece na Companhia de Jesus um catálogo próprio: vd. ALLEGAM BE, P, Heroes et victimae charitatis Soc. lesu seu Catalogus eorum qui e Societate lesu charitati animum deuouerunt ad id expositi et immortui peste infectorum obsequio ex charitate obedientiaque suscepto..., Romae, 1658.

(33) Padecidos ... XII, v. I 30- 140.

(34) Cf. Padecidos... XII, v. 172-178: “Ah Fénix, como partes feliz! como desprezas as iras de vulcano, e rejubilas de renascer das chamas! Como voas formosa e resplandecente! sobes acima da própria Lua e do Sol, com tuas asas vais além dos astros dourados, da cristalina abóbada celeste, os olhos dos que te seguem já não podem distinguir-te. Parte, bem-aventurado, exulta para sempre no triunfo que alcançaste." 
e S. Francisco Xavier. Espera o herói um trono admirável que, à maneira do escudo de Aquiles ou do de Eneias, é também de fabrico divino. No bronze desta obra brilham Portugal, a India, a China, as cidades do Japão, os trabalhos e a vida de Pacheco, a sua morte, e na base do trono estão esmagados os monstros cruéis das divindades japonesas, inimigos vencidos.

O poema termina em apoteose. Na perspectiva do humanismo da Contra Reforma, este mártir-herói merece ser cantado, é exemplum de virtude, venceu o desafio dos seus limites e da sua caducidade, paradoxalmente, pela morte. O combate que travou preparado pela ascese, deu-lhe a vitória. Esta é, sem dúvida, uma manifestação de espírito agónico, do princípio humano que leva o homem a esforçar-se por superar os seus limites, por corresponder ao seu fim, e que ao longo da história humana pode resultar nos mais elevados ideais. 